\title{
A Tribute to Thomas B. Sanford (1940-2020)
}

Tom Sanford brought an innovative mind to ocean science. His passion was measuring ocean currents with electromagnetic sensors. This interest led him first to develop a theory for electric currents driven by the flow of conductive seawater in Earth's magnetic field so that measurements could be correctly interpreted, then to design sensors that could measure down to nanovolt accuracy through clever electrode configurations and state-of-the-art low-noise amplifiers using cutting-edge 1970s transistors and integrated circuits.

Throughout his career, Tom always sought ways to improve electrode performance and make measurements that were inaccessible to standard ocean instruments and sampling. He conceived and deployed over a dozen instrument platforms to measure the vertical, horizontal, and temporal structure of ocean flows in the surface mixed layer, stratified interior, and bottom boundary layer, and devised a means to directly measure vorticity and vorticity flux in turbulent boundary layers. Tom proved the feasibility of using a seafloor cable to monitor Florida Current transport, demonstrating its large intra- and interannual variability, and leading to longterm monitoring of the Atlantic Meridional Overturning Circulation.

While most of the community was focusing on moored time series in the 1970s, Tom built profilers to uncover the rich vertical and horizontal structure of internal wave motions in groundbreaking work that refined the shape of the internal wave spectrum, established the vertical asymmetry of near-inertial waves from the spiraling of the horizontal velocity vector with depth that has been called the "double helix of physical oceanography," and described the three-dimensional velocity structure of meso- and submesoscale eddies and boundary currents. His full-depth profilers were later used to study internal tide generation and propagation, identifying the Hawaiian Ridge as a major source of internal tide energy in the North Pacific, and he helped to establish a widespread relationship between finescale internal waves and ocean turbulence.

Recognizing the limitations of a recoverable profiler, Tom designed an expendable profiler that could be rapidly deployed in heavy seas from ships underway and aircraft. This instrument gained wide use as a submesoscale survey tool for studying the upper ocean's response to storms and hurricanes, near-inertial wave interactions with fronts and eddies, flow-topography interactions such as the impacts of bottom drag and interfacial mixing on the Mediterranean and Denmark Strait outflow plumes, and turbulent dissipation and mixing inferred from a finescale parameterization.

In the last decade, Tom's projects included (but were by no means limited to) augmenting arrays of autonomous profiling floats to measure velocity electromagnetically (EM-APEX) and turbulence with temperature microscale sensors, adding electromagnetic sensors to pressure-gauge-inverted echo sounders (PIES) to measure depthaveraged velocities remotely, and designing an electromagnetic source and sensor array to remotely measure salt wedge variability in river estuaries. His EM-APEX profiling floats have seen wide use, deployed in arrays to make four-dimensional measurements of the submesoscale partition between internal waves and balanced flow, wind generation of internal waves, the evolution of the surface boundary layer, and motions under Antarctic ice. After retiring at 75, he bicycled into the office almost every day to continue developing innovative instruments and conduct fundamental oceanographic research from their data.

Tom earned his undergraduate degree in physics in 1962 and his $\mathrm{PhD}$ in mathematics and oceanography with Bill von Arx in 1967. For his scientific and engineering contributions, as well as service on numerous professional committees and as a founding editor for the Journal of Atmospheric and Oceanic Technology, Tom was made a fellow of both the American Geophysical Union and American Meteorological Society. He received the AMS Henry Stommel Research Award and IEEE/OES Distinguished Technical Achievement Award, and was

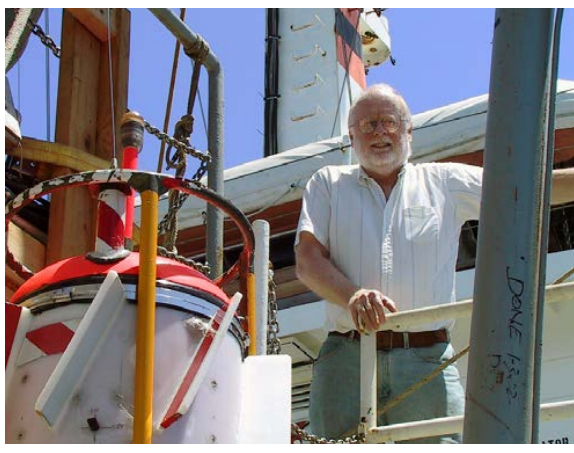

Tom Sanford aboard R/V Wecoma with his fulldepth absolute velocity profiler during the 2000 Hawaii Ocean Mixing Experiment (HOME).

the Secretary of the Navy/Chief of Naval Operations Chair in Ocean Sciences. Tom was among those who formed The Oceanography Society in 1988, joining as a life member.

For those fortunate to be his collaborators, Tom was an insightful, generous, and kind colleague. Three of his engineers, John Dunlap, Bob Drever, and Art Bartlett, left New England to join him in Seattle, later to be joined by Jim Carlson and Avery Snyder, drawn by the exciting challenges he posed them and the professional rewards of working in his group. He valued all of his many collaborations but perhaps especially those with Tom Rossby, Jim Larsen, Mike Gregg, Jim Price, Rolf Käse, Ann Gargett, Eric D'Asaro, and Peter Spain. He had high standards and pushed everyone around him to do their best, particularly when it came to making the most of seagoing data collection. Tom always acknowledged credit where it was due and tirelessly did everything he could to help his 14 graduate students, nine postdoctoral advisees, and many other early career colleagues get their professional start. As an advisor, Tom gave students and postdocs opportunities to collect their own data and find their own scientific paths. As a collaborator, he did more than his share. As a friend, he could be counted on for advice and support. Tom pulled back the curtain of theory and equations to show us the rich variability of the real ocean. The oceanographic community and world are smaller without him. @

Contributed by Eric Kunze and Ren-Chieh Lien 